\title{
JGZ-richtlijn Vroegtijdige opsporing van gehoorverlies bij kinderen en jongeren ( 0 tot 18 jaar)
}

\author{
C. I. Lanting · J. A. Deurloo - C. H. Wiefferink · N. Uilenburg
}

Published online: 18 July 2017

(C) Bohn Stafleu van Loghum 2017

Samenvatting In juni 2016 werd de JGZ-richtlijn Vroegtijdige opsporing van gehoorverlies bij kinderen en jongeren (0 tot 18 jaar) gepubliceerd. Met deze richtlijn is de JGZ-standaard Vroegtijdige opsporing van gehoorstoornissen 0 tot 19 jaar (1998) komen te vervallen. De nieuwe richtlijn biedt JGZ-professionals praktische handvatten bij de signalering van gehoorverlies na de neonatale periode.

Trefwoorden audiometrie $\cdot$ gehoor $\cdot$ screening

\section{Waarom deze richtlijn?}

Permanent gehoorverlies kan grote gevolgen hebben voor de ontwikkeling. Kinderen met ernstig permanent gehoorverlies (vanaf $60 \mathrm{~dB}$ ) hebben geen toegang tot gesproken taal; hoorhulpmiddelen, het aanleren van gebarentaal en intensieve begeleiding zijn nodig om tot ontwikkeling te komen. Ook matig permanent gehoorverlies (41-60 dB) kan negatieve gevolgen hebben voor de taalontwikkeling en de schoolprestaties. Kinderen met een matig gehoorverlies ondervinden bovendien meer problemen op het sociaal-emotionele vlak dan horende kinderen, ze hebben vaker gedragsproblemen, ze tonen vaker signalen van stress en hebben een lagere zelfwaardering.

Naar schatting wordt een op de duizend baby's geboren met een gehoorverlies van minimaal $40 \mathrm{~dB}$ aan beide oren. In Nederland zijn dat 180-215 baby's per jaar [1]. Bij kinderen die worden behandeld in een neonatale intensive care unit (NICU) is de preva-

\footnotetext{
C. I. Lanting $(\bowtie) \cdot$ J. A. Deurloo

TNO, Leiden, Nederland

caren.lanting@tno.nl

C. H. Wiefferink · N. Uilenburg

NSDSK, Amsterdam, Nederland
}

lentie van permanent gehoorverlies ongeveer 25 keer zo hoog als bij gezonde pasgeborenen [2]. Sinds 2002 wordt daarom het gehoor gescreend van baby's die langer dan 24 uur op de NICU hebben gelegen [3]. Sinds 2006 is in heel Nederland de neonatale gehoorscreening (NGS) voor gezonde zuigelingen ingevoerd [4]. De NGS voor alle pasgeborenen wordt uitgevoerd door de jeugdgezondheidszorg (JGZ). Een gunstige uitkomst van de NGS is echter geen garantie voor een goed gehoor op de kinderleeftijd [5]. Kinderen met gehoorverlies kunnen gemist worden bij de NGS. Ook kan gehoorverlies zich pas op latere leeftijd ontwikkelen waardoor het bij de NGS nog niet ontdekt kon worden. Op basis van een Engelse studie is de verwachting dat het aantal kinderen met gehoorverlies verdubbelt vanaf de neonatale periode tot de leeftijd van 9 jaar [6]. Ook voor deze groep kinderen is het van belang dat het gehoorverlies zo snel mogelijk wordt ontdekt, zodat ook zij snel met behandeling kunnen starten.

\section{Uitgangsvragen}

De JGZ-richtlijn Vroegtijdige opsporing van gehoorverlies bij kinderen en jongeren (0 tot 18 jaar; [7]) is gebaseerd op een knelpuntenanalyse onder professionals. De knelpunten zijn vertaald naar de volgende uitgangsvragen, waarop in de nieuwe richtlijn een antwoord wordt gegeven.

1. Welke informatie dient te worden overgedragen tussen NICU's en de regiocoördinator JGZ?

2. Wat zijn risicofactoren voor gehoorverlies dat zich na de NGS manifesteert?

3. Is er een effectieve screeningsmethode voor het vaststellen van lichte, maar progressieve gehoorverliezen en auditieve neuropathie door de JGZ bij kinderen van 0 tot 8 jaar? 
4. Welke kennis over de mogelijke oorzaken van breed gedefinieerde problematiek (bijvoorbeeld gedragsproblemen of taalproblemen) hebben personen in het netwerk van kinderen in de leeftijd van 2 tot 8 jaar nodig om gehoorverlies vast te kunnen stellen? Wat is de rol van de JGZ hierin?

5. Leidt een extra screening in de tijd tussen de NGS en de screening op de basisschool tot het tijdiger detecteren van gehoorverlies bij kinderen?

6. Wat zijn criteria voor adequate opsporing en verwijzing om de (mate van) gehoorverlies bij kinderen van 4 tot 6 jaar tijdig vast te kunnen stellen?

7. Welke gehoormeting, welke apparatuur en welke omstandigheden zijn het meest adequaat voor een gehoorscreening door de JGZ bij kinderen in groep 2?

8. Wat is de effectiviteit van interventies die tot doel hebben om gehoorschade door hard geluid te voorkomen of te beperken bij kinderen vanaf de basisschoolleeftijd?

9. Op welke leeftijd in de periode na de NGS tot 18 jaar moet op basis van welke criteria doorverwezen worden naar welk gremium om goede zorg voor kinderen met gehoorverlies te kunnen waarborgen?

10. Hoe kan gehoorverlies door hard geluid bij kinderen van 12 tot 18 jaar effectief worden opgespoord?

\section{Opbouw van de richtlijn en aanbevelingen}

De richtlijn omvat vier thema's: werking van het gehoor en gehoorverlies, NGS, signalering van gehoorverlies na de neonatale periode (waarbij onderscheid wordt gemaakt naar kinderen in de leeftijd van 0 tot 4 jaar en kinderen van 4 jaar en ouder) en preventie van gehoorverlies door hard geluid.

De NGS voor alle pasgeborenen wordt uitgevoerd door de JGZ [8]. Uitzondering hierop zijn kinderen die na de geboorte langer dan 24 uur op een NICU verblijven. Bij hen wordt de gehoorscreening uitgevoerd door een NICU-medewerker. Voor het vervolg van de zorg en om te voorkomen dat (ex-) NICU-kinderen niet of dubbel worden gescreend is het nodig dat de JGZ op de hoogte is van de uitslag van de NICU-screening. De richtlijn beveelt aan om regionale afspraken te maken over de manier waarop het beste informatie kan worden uitgewisseld tussen JGZ en NICU totdat digitale uitwisseling is gerealiseerd.

Bij kinderen tot de leeftijd van 4 jaar vindt opsporing van gehoorverlies plaats op basis van risicofactoren en indirect via bijvoorbeeld gedragsproblemen, concentratieproblemen, taalproblemen en vermoeidheid. De JGZ registreert tijdens het eerste huisbezoek en bij het eerste contact met de jeugdarts of permanent gehoorverlies ( $<40$ jaar) in de familie voorkomt, en of er bijzonderheden waren tijdens zwangerschap (infecties, medicatie) en partus (ernstige asfyxie). Bij kinderen waarbij sprake is van een of meerdere risico-

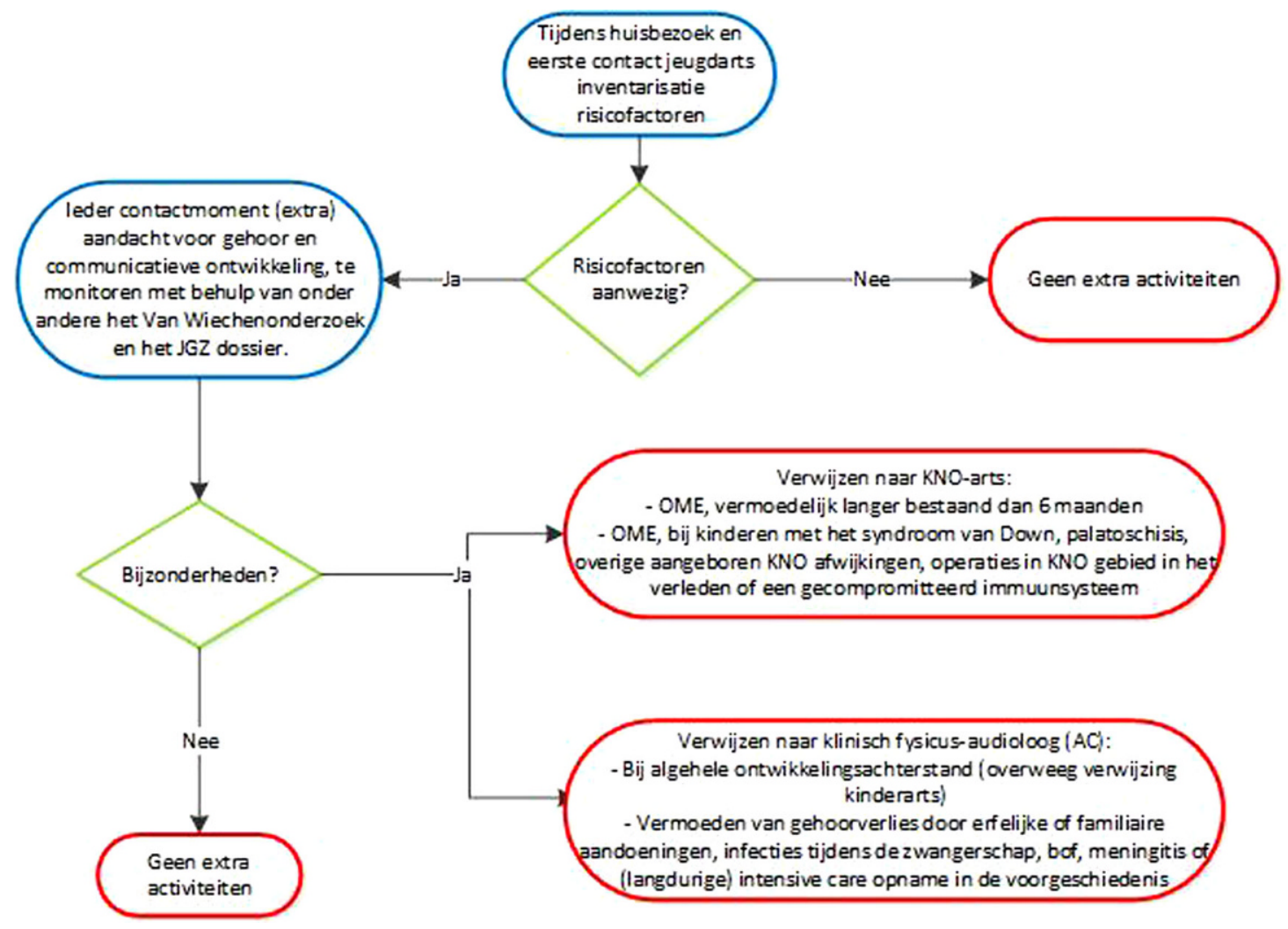

Figuur 1 Stroomschema JGZ-richtlijn gehoor 0-4 jaar 


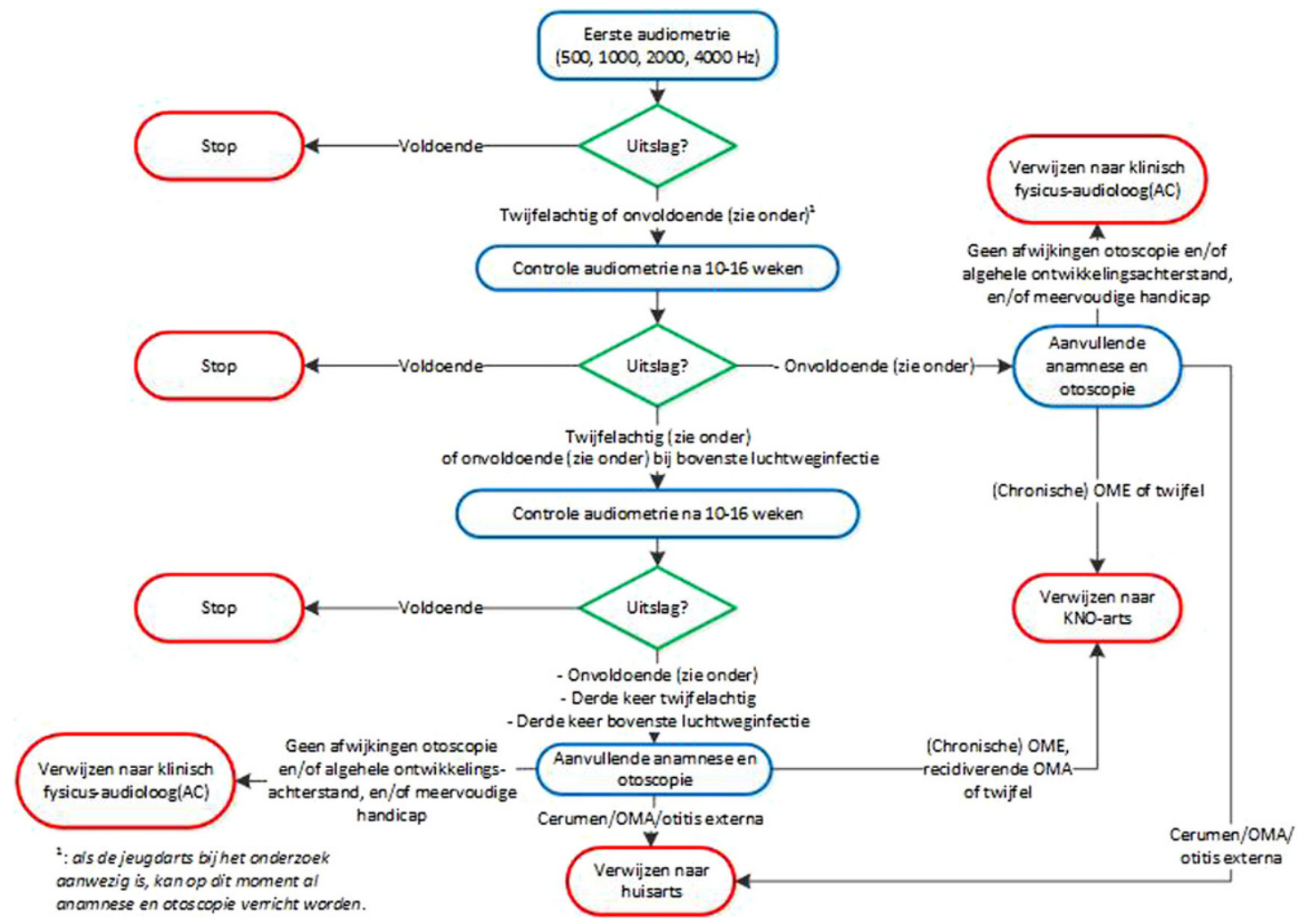

Figuur 2 Stroomschema JGZ-richtlijn gehoor 4 jaar en ouder

factoren is er tijdens ieder contactmoment aandacht nodig voor het gehoor en de communicatieve ontwikkeling, te monitoren met behulp van het Van Wiechenonderzoek en het JGZ-dossier. De combinatie van achterblijvende communicatieve ontwikkeling en de aanwezigheid van één of meer risicofactoren is een reden om te verwijzen. Bij herhaalde twijfel over het bestaan van gehoorverlies wordt afhankelijk van de uitslag van otoscopie verwezen naar een klinisch fysicus-audioloog (in een audiologisch centrum) of een KNO-arts (fig. 1).

Vanaf de leeftijd van ongeveer 4 jaar voert de JGZ gehoormeting uit: 1. tijdens regulier(e) contactmoment(en): ten minste eenmaal bij alle kinderen van 4 tot en met 6 jaar oud; 2 . op indicatie bij kinderen van 4 jaar of ouder. Gehoormeting wordt uitgevoerd met drempelaudiometrie volgens de descending methode voor de frequenties 500, 1000, 2000, $4000 \mathrm{~Hz}$. Bij de drempelaudiometrie wordt niet meer getest op de frequentie van $6000 \mathrm{~Hz}$ omdat dit niet tot het spraakgebied behoort. De criteria voor controle en verwijzing zijn ten opzichte van de Standaard uit 1998 aangescherpt, zie hiervoor de samenvattingskaart van de richtlijn [7]. Mogelijke vervolgstappen zijn: geen verdere actie (bij voldoende resultaat), controle audiogram of verwijzen na anamnese en lichamelijk onderzoek (inclusief otoscopie; fig. 2).

Ondanks dat er nauwelijks wetenschappelijk bewijs is voor de effectiviteit van preventieve interventies wordt in de richtlijn de noodzaak benoemd om jeugdigen bewust te maken van risico's van blootstelling aan hard geluid. Collectieve preventie door GGD en gemeente is daarbij het meest aangewezen. De JGZ inventariseert bij jongeren op de middelbare school tenminste een keer het gehoorgedrag met behulp van een vragenlijst. Op basis daarvan kan de GGD en gemeente beoordelen welke groepen meer risico lopen om zo gerichter educatie en voorlichting te kunnen geven.

\section{Praktijktest en randvoorwaarden voor implemen- tatie}

De nieuwe richtlijn is in 2015 in de praktijk getest door vijf JGZ-teams en negen JGZ-professionals (totaal 44 personen) werkzaam bij JGZ-organisaties verspreid over heel Nederland. Na instructiebijeenkomsten werkten de JGZ-professionals voor een periode van 4 á 5 maanden met de richtlijn. Evaluatie vond plaats aan de hand van registratieformulieren, een vragenlijst en tijdens groepsinterviews. De richtlijn bleek voor de JGZ-professionals goed uitvoerbaar, vooral het inventariseren van risicofactoren en het uitvoeren van drempelaudiometrie. Belangrijkste knelpunt was dat de drempelaudiometrie veel tijd kost doordat veel kleuters zich niet lang kunnen concentreren. Hieraan werd tegemoet gekomen door in de definitieve richtlijn een wat beknoptere werkwijze voor de audiometrie op te nemen. Een belangrijke randvoorwaarde voor gebruik van de richtlijn is dat 
de audiometrie in een stille ruimte afgenomen kan worden. Voor de implementatie van de richtlijn is het verder van belang dat professionals voldoende tijd en mogelijkheid krijgen om zich te verdiepen in de richtlijn, inclusief lezen en een instructiebijeenkomst. Ook helpt het als professionals de richtlijn zo nu en dan bespreken met collega's. Hoewel de digitale vorm van de richtlijn goed werkt, blijven JGZ-professionals behoefte houden aan het stroomdiagram, de beschrijving van de drempelaudiometrie en de risicofactoren op papier.

\section{Meer informatie?}

De JGZ-richtlijn Vroegtijdige opsporing van gehoorverlies bij kinderen en jongeren ( 0 tot 18 jaar) is ontwikkeld door TNO in samenwerking met de Nederlandse Stichting voor het Dove en Slechthorende Kind (NSDSK). De richtlijn is gefinancierd door ZonMw. Voor de volledige tekst en de ondersteunende producten zoals werkkaart, een powerpoint-presentatie voor instructiedoeleinden en een BDS-registratieprotocol, zie: www.jgzrichtlijnen.nl. Hier vindt u ook gegevens over de auteurs en de totstandkoming van de richtlijn.

\section{Literatuur}

1. RIVM. monitor neonatale gehoorscreening 2010 e.v 2010. www.rivm.nl/gehoorscreening. Geraadpleegd op: 1 mei 2017.

2. Dommelen P van, Straaten HL van, Verkerk PH, Dutch NICU Neonatal Hearing Screening Working Group. Ten- year quality assurance of the nationwide hearing screening programme in dutch neonatal intensive care units. Acta Paediatr. 1992;100:1097-103.

3. Straaten HL van, Hille ET, KokJH, Verkerk PH, Dutch NICU Neonatal Hearing Screening Working Group. Implementation of a nation-wide automated auditory brainstem response hearing screening programme in neonatal intensive care units. Acta Paediatr. 1992;92:332-8.

4. Kauffman-de Boer M, Uilenburg N, Schuitema T, Vinks E, Brink G van den, Ploeg K van der. et al. Landelijke implementatie neonatale gehoorscreening. Amsterdam: NSDSK; 2006.

5. Korver AHM, Van Zanten GA, Meuwese-Jongejeugd A, Straaten HLM van, Oudesluys-Murphy AM. Auditory neuropathy in a low-risk population: a review of the literature. Int J Pediatr Otorhinolaryngol. 2012;76:1708-11.

6. FortnumH,DavisA. Epidemiology of permanentchildhood hearingimpairment in TrentRegion, 1985-1993. BrJAudiol. 1997;31(6):409.

7. Lanting CI, Deurloo JA, WiefferinkK, Uilenburg N. Richtlijn 'Vroegtijdige opsporing van gehoorverlies bij kinderen en jongeren (0 tot 18 jaar) 2016' 2016. www.jgzrichtlijnen.nl. Geraadpleegd op: 1 mei 2017.

8. RIVM. Draaiboek Neonatale Gehoorscreening Jeugdgezondheidszorg 2017. www.rivm.nl/Documenten en_publicaties/Professioneel_Praktisch/Draaiboeken/ Preventie_Ziekte_Zorg/Gehoorscreening/Draaiboek_Neo natale_Gehoorscreening_Jeugdgezondheidszorg_v7. Geraadpleegd op: 1 juli 2017.

C.I. Lanting, arts-epidemioloog/richtlijnontwikkelaar.

J.A. Deurloo, wetenschappelijkmedewerker en jeugdarts.

C.H. Wiefferink, senior onderzoeker.

N. Uilenburg, manager R\&D. 